\title{
Electron Probe Micro-Analysis of a Contact Probe after Er:YAG Laser Tooth Ablation
}

\author{
Toru EGURO, Toru MAEDA ${ }^{1}$, Masaaki OGAWA ${ }^{2}$, \\ Kazuaki YONEMOTO ${ }^{3}$, Hisayoshi TANAKA ${ }^{3}$ and Ichiroh KATSUUMI \\ Department of Endodontics \& Operative Dentistry, \\ School of Dentistry at Tokyo, Nippon Dental University \\ 2-3-16 Fujimi, Chiyoda-ku Tokyo, 102-8158 Japan \\ ${ }^{1}$ Division of General Dentistry, Nippon Dental University Dental Hospital \\ 2-3-16 Fujimi, Chiyoda-ku Tokyo, 102-8158 Japan \\ ${ }^{2}$ Dental Research Institute, Nippon Dental University \\ 1-9-20 Fujimi, Chiyoda-ku Tokyo, 102-8159 Japan \\ ${ }^{3}$ Graduate School of Dentistry at Tokyo, Nippon Dental University \\ 1-9-20 Fujimi, Chiyoda-ku Tokyo, 102-8159 Japan
}

Received October 15, 2002/Accepted December 25, 2002

\begin{abstract}
The purpose of this study was to investigate the contact probes of Er:YAG laser before and after tooth ablation. Three kinds of contact probe were prepared. The first was an unused probe (NE). The second was used to prepare 10 cervical cavities (KP). The third was a probe that was judged for an exchange by three dentists who had expertise with Er:YAG laser (EX). The surface observation and mapping analysis were performed. The contact surface of NE was a flat and smooth surface, only $\mathrm{Si}$ was observed. KP demonstrated an uneven surface, Si was observed throughout, with scattered indications of $\mathrm{Ca}$ and P. EX displayed regions of fracture along the edge and a surface exhibiting dissolved adherents in parts. It was suggested that micro-explosions have effects on not only the tooth substance, but also the contact surface of the probe.
\end{abstract}

Key words : Contact probe, Er:YAG laser, EPMA analysis

\section{INTRODUCTION}

Treatment of dental caries using the Er:YAG laser has recently become widespread $^{1-5)}$. This laser has been widely applied to endodontic and periodontic therapy, oral surgery and dental implant treatment, in addition to the treatment of dental caries $^{6-12)}$. Furthermore, various studies to develop and improve apparatus, handpieces and contact probes have been conducted. For ablation of tooth substances, two kinds of systems exist. One system does not use a contact probe, utilizing a red diode laser for guidance. The other system uses some kind of contact probe, with or without a He-Ne laser, diode laser, or flash lamp for guidance. More than twelve years has passed since Er:YAG laser was first applied to dentistry in $1988^{13)}$. The KaVo K.E.Y. Laser 1240 (KaVo, Biberach, Germany) appeared on the market in 1992, marking the beginning of commercial applications in dental practice. This model was upgraded to the KaVo K.E.Y. Laser 1242 in 1994, and the KEY Laser 3 in 2001. These models utilize a noncontact handpiece for ablation of tooth 
substances. Competing with these noncontact systems, the ErWin (Morita Co. \& HOYA, Tokyo, Japan) went on sale in Japan in 1996, with the Centauri (Premier Laser Systems, Inc., CA, USA), DElight (Contenium, CA, USA), Dentlite (HOYA Contenium, Tokyo, Japan), Opus 20 (Lumenis, Yokneam, Israel), Fidelis model 320 (Fotona, Ljubljana, Slovenia) and ELfine400 (Osada Electronic, Tokyo, Japan) following. These models provide irradiation using contact probes. Opinion regarding contact and noncontact systems has varied from the outset. We have used both systems in our department, and have come to the following conclusions regarding their respective advantages and disadvantages. Noncontact systems do not require replacement of contact probes, as contact is not made with the target surface. However, some problems exist. The focus of the diode laser used for guidance becomes indistinct, in case of pits and fissures. Uncontrast, the contact system does not rely on guidance lights and can transmit the sense of touch of the ablated surface to the fingers, and it was considered that ablation efficiency of the contact probe gradually decreases with use.

Although numerous studies have reported the effects of Er:YAG laser irradiation on tooth and surrounding tissues, little information is available regarding contact probes. The present study investigated the surface observation and mapping analysis of contact probes of Er:YAG laser before and after tooth ablation using an Electron Probe Micro Analyzer.

\section{MATERIALS AND METHODS}

For the Er:YAG laser apparatus, a Dentlite with an $80^{\circ}$ curved contact probe (HOYA Contenium, Tokyo, Japan) was utilized. Duration of the laser pulse was approximately $200 \mu \mathrm{sec}$, and beam diameter was approximately $600 \mu \mathrm{m}$. The $80^{\circ}$ curved contact probe was $600 \mu \mathrm{m}$ in diameter, consisting of quartz crystal. Three kinds of contact probe were prepared. The first was a new, unused probe (NE). The second was used to prepare 10 cervical U-shaped cavities (KP). The third was the probe that was judged for an exchange by three dentists who had expertise with Er:YAG laser, because the regions of fracture along the edge were observed by the naked eye and ablation efficiency of the probe was clearly decreased (EX).

Surface observations and mapping analyses of contact probes were performed using an EPMA-8705 (SHIMADZU, Kyoto, Japan). Surfaces of contact probes were coated with $\mathrm{C}$, and an acceleration voltage of $20 \mathrm{kV}$ was used to observe surfaces. Mapping analyses of the contact surface of the probe were performed for $\mathrm{Si}, \mathrm{Ca}$ and $\mathrm{P}$ under a sample current of $10 \mathrm{nA}$ and an acceleration voltage of $20 \mathrm{kV}$, using characteristic X-rays of $\mathrm{Si} \mathrm{K} \alpha, \mathrm{Ca} \mathrm{K} \alpha$ and $\mathrm{P} \mathrm{K} \alpha$, respectively. No cleaning or other treatments was performed on any of the contact probes prior to evaluation.

\section{RESULTS}

Photomicrographs of surface observations are shown in Fig. 1. For NE, the contact 


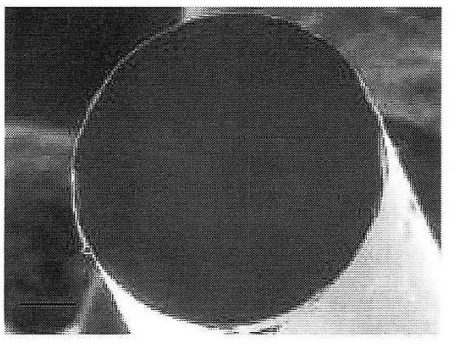

a

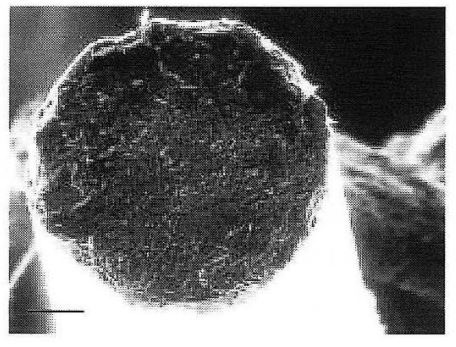

$\mathrm{b}$

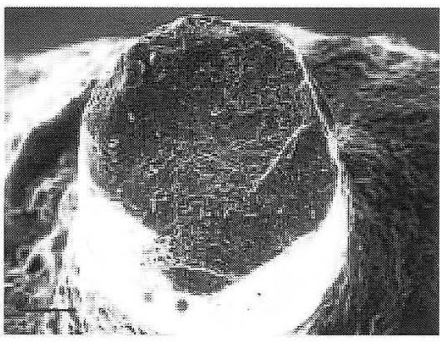

c

Fig. 1 Photomicrographs of the contact surface of various contact probes. a: NE probe, b: KP probe, c: EX probe bur: $100 \mu \mathrm{m}$, original magnification: $\times 80$

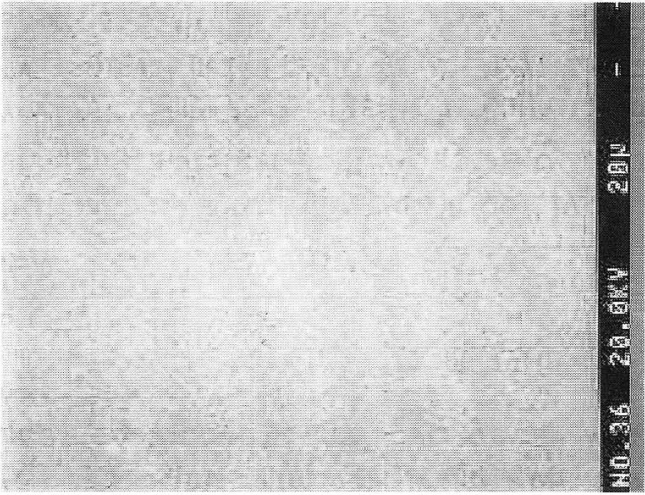

a

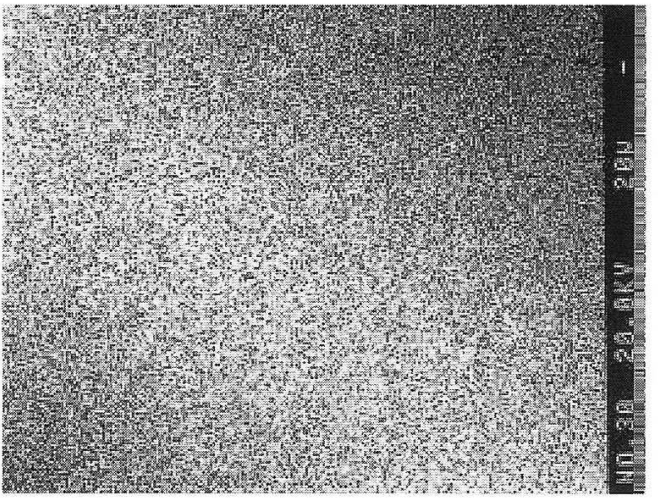

b

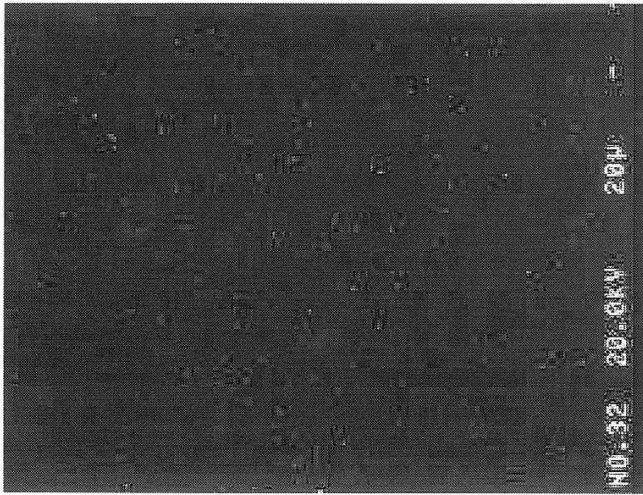

C

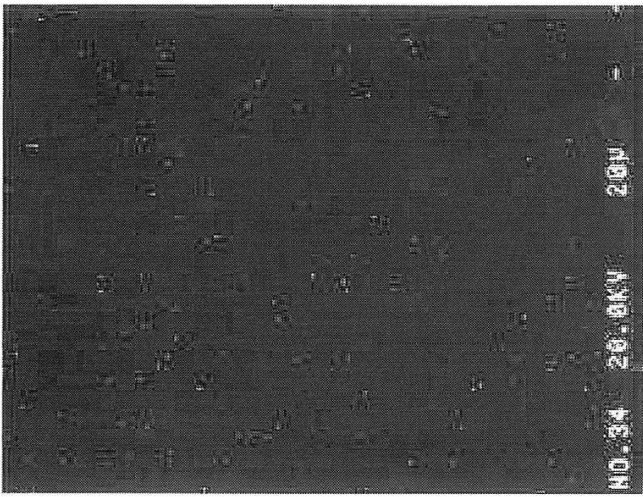

d

Fig. 2 Results of mapping analysis on NE surface. a: photomicrograph of SEM (original magnification: $\times 500$ ) $\mathrm{b}$ : result of $\mathrm{Si}, \mathrm{c}$ : result of $\mathrm{Ca}, \mathrm{d}$ : result of $\mathrm{P}$ 
surface of the probe was nearly circular, with a flat and smooth surface. KP demonstrated arounded edge and uneven surface. EX displayed regions of fracture along the edge and a surface exhibiting dissolved adherents in parts.

Results of EPMA analyses for the 3 kinds of contact probe are shown in Figs 2-4. For NE, only Si was observed, with no Ca or P detected. For KP, Si was observed throughout, with scattered indications of $\mathrm{Ca}$ and $\mathrm{P}$. For EX, Si predominated, but proportions of $\mathrm{Ca}$ and $\mathrm{P}$ were increased compared with $\mathrm{KP}$. Ca and $\mathrm{P}$ were detected in the same regions as the adherents identified in surface observations.

\section{DISCUSSION}

At present, quartz- or sapphire-crystal rods are utilized as contact probes for Er:YAG laser. The $80^{\circ}$ curved contact probe of the Dentlite used in the present study consists of quartz crystal, but detailed characteristics are not known. We conducted surface observations and mapping analyses. We analyzed Si that composes the quartz rod, $\mathrm{Ca}$ and $\mathrm{P}$ that compose the tooth substance, as part of the ablated tooth substance that adhered to the surface of the contact probe. The unused NE contact probe demonstrated a flat, smooth contact surface. According to the manufacturer, the surface should be polished to a mirror-smooth state using $3-\mu \mathrm{m}$ diameter diamond paste. Surface analyses using EPMA detected Si over the entire surface, with no $\mathrm{Ca}$ or $\mathrm{P}$ (Fig.2). Some points shown in analyses of $\mathrm{Ca}$ and $\mathrm{P}$ were suggested attributable to background effects. After preparing 10 cervical cavities, the contact surface of $\mathrm{KP}$ was roughened, mapping analysis of the contact surface of $\mathrm{KP}$ detected $\mathrm{Ca}$ and $\mathrm{P}$ in addition to $\mathrm{Si}$. This result suggests the tooth substance adheres to the contact surface of the probe after ablation. The time at which a contact probe should be exchanged varies with individual operators, because no definite guidelines exist. In this study, EX probes were judged by 3 clinicians who frequently use Dentlite and have profound knowledge of Er:YAG lasers. For EX, a large fracture region was observed at the edge of the contact surface and dissolved adherents were found in part.

Nelson et al. stated in their study of bone ablation that some vapor produced by the laser energy will buildup internal pressure caused by heat and a micro-explosion will occur with part of the substrate being ejecting in the form of microscopic particles $^{13)}$. With regard to the mechanisms of hard substances removal using Er:YAG laser, Keller et al. supported their suggestion and reported that the same process took place in enamel and dentin ${ }^{14)}$. When the contact probe touches the tooth surface, it is suggested that micro-explosions have effects on not only the tooth substance, but also the contact surface of the probe. Surface analysis detected Ca and $\mathrm{P}$ in the same region as these adherents, which were consequently considered to be tooth substance adhered to the contact probe following ablation.

This study revealed that the contact surfaces of probes change in morphology and the ablated tooth substance adheres to the contact surface with use. These changes would appear to decrease output energy of the probe and ablation efficiency 


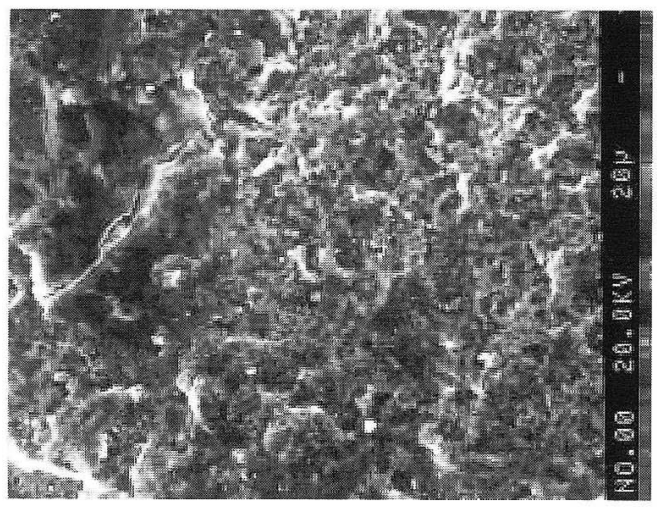

a

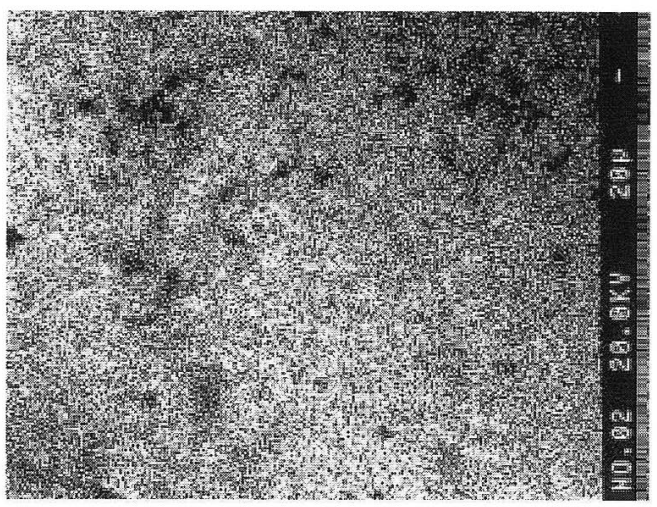

$\mathrm{b}$
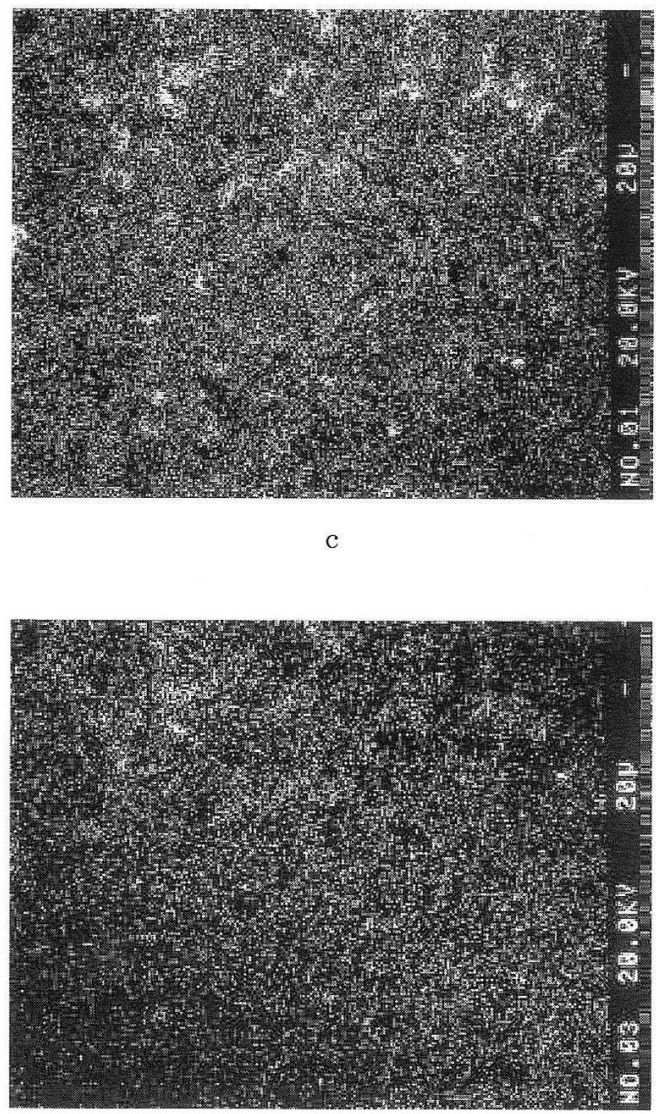

d

Fig. 3 Results of mapping analysis on the KP surface.

a: photomicrograph of SEM (original magnification: $\times 500$ )

$\mathrm{b}$ : result of $\mathrm{Si}, \mathrm{c}$ : result of $\mathrm{Ca}, \mathrm{d}$ : result of $\mathrm{P}$

of tooth substance. Maeda et al. measured the output energy changes with tooth ablation, the output energy showed the $80.2 \%$ of the initial energy after $5 \#$ minutes use with enamel ablation, and $49.4 \%$ after $100 \#$ minutes ${ }^{16)}$. It was reported that ablation efficiency depends on the output energy, such that a higher energy irradiaton is able to produce a deeper crater $^{13,17}$.

We infer that the deterioration of contact probes varies, depending on conditions such as irradiated objects, irradiated energy, force of application to the tooth surface and the availability of spray atomization during irradiation. We intend to examine how to remove adhered substances, and to compare the output energy changes of quartz rods with that of sapphire rods in future studies. 


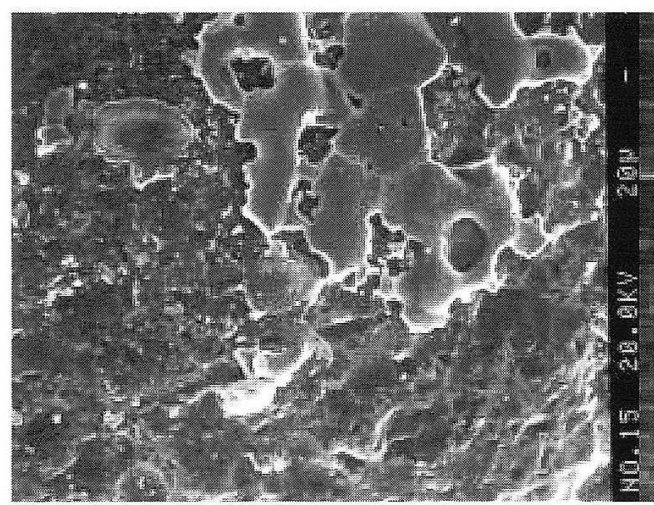

a

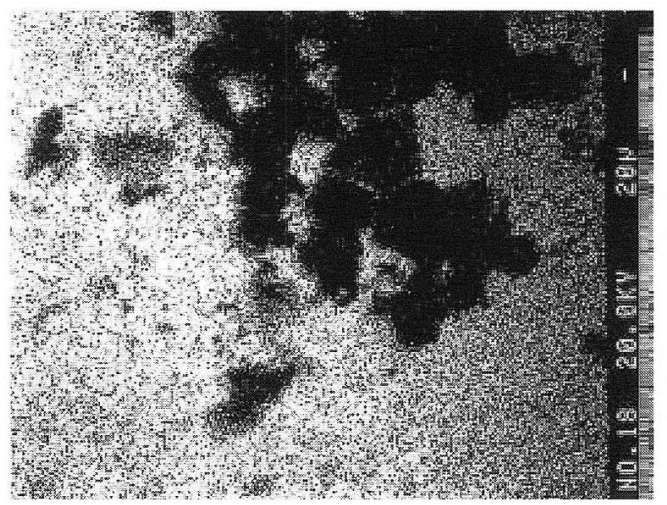

b

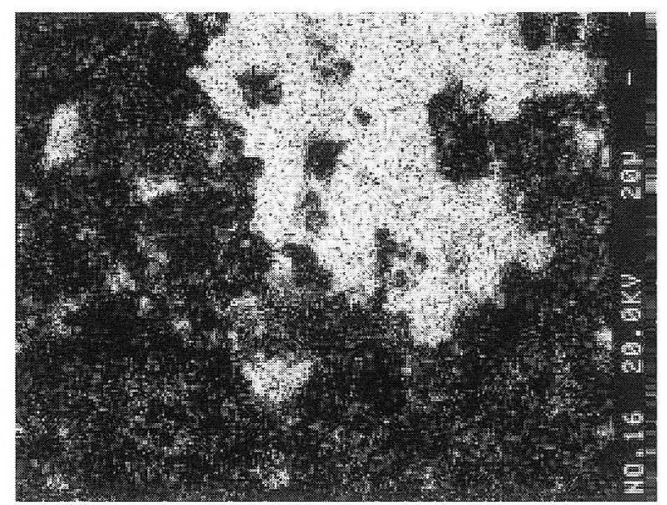

c

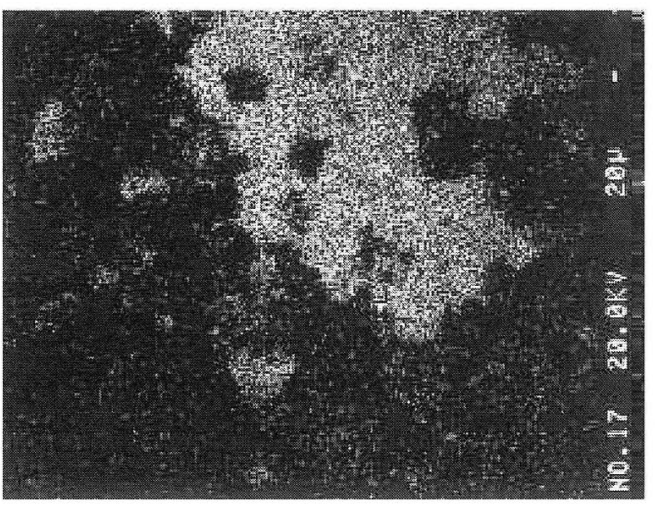

d

Fig. 4 Results of mapping analysis on EX surface.

a: photomicrograph of SEM (original magnification: $\times 500$ )

b: result of $\mathrm{Si}, \mathrm{c}$ : result of $\mathrm{Ca}, \mathrm{d}$ : result of $\mathrm{P}$

\section{REFERENCES}

1) Takizawa, M., Aoki, S., Takase, Y., et al.: Clinical evaluation of Er:YAG laser for cavity preparation, $J J$ Conserv Dent $38: 1035-1047$, 1995. (in Japanese)

2) Dostálová, T., Jelínková, II., Kučerová, II., Krejsa, O., IIamal, K., Kubelka, J. and Procházka, S.: Noncontact Er:YAG Laser Ablation; Clinical Evaluation, J Clin Laser Med Surg 16 : 273-282, 1998.

3) Ishimaru, K., Sakamoto, T., Iwase, H., et al.: Clinical Evaluation of Caries Treatment with Er:YAG Laser, $J J$ Conserv Dent 43:892-907, 2000. (in Japanese)

4) Keller, U., Hibst, R., Geurtsen, W., et al.: Erbium:YAG laser application in caries therapy. Evaluation of patient perception and acceptance, J Dent 26:649-656, 1998.

5) Eguro, T., Namekawa, H., Nogami, I., Warita, K. and Maeda, T.: Ablation of dental hard tissue by The KaVo K.E.Y. Laser, $J$ J Conserv Dent 38:1339-1346, 1995. (in Japanese)

6) Paghdiwala, A. F.: Root Resection of Endodontically Treatment Teeth by Erbium: YAG Laser Radiation, J Endodontics 19(2): 91-94, 1993. 
7) Aoki, A., Ando, Y., Watanabe, H. and Ishikawa, I.: In vitro studies on laser scaling of subgingival calculus with an Er:YAG laser. J Perodontal 65 : 1097-1106, 1994.

8) El-Moutase, M., Devlin, H., Dickinson, M. R., Sloan, P. and Lloyd, R. E.: Osseointegration of titanium metal implants in Erbium-YAG laser-prepared bone, Implant Dent 8(1) : 79-85, 1999.

9) Shoji, S., Hariu, H. and Horiuchi, H.: Canal enlargement by Er:YAG laser using a coneshaped irradiation tip, $J$ Endod 26(8) : 454-458, 2000.

10) Eguro, T., Ogawa, M., Yanase, T., Kubo, K., Maeda, T. and Tanaka, H: The effect of the Er:YAG Laser Irradiation on Fixtures of Oral Implant, $J J$ Soc Oral Implantlogy $12: 504-510,1999$. (in Japanese)

11) Matsuyama, T., Aoki, A., Oda, S., Hamanaka, H. and Ishikawa, I.: Application of Er:YAG Laser for Implant Maintenance Therapy, Proceeding of $5^{\text {th }}$ WCOI congress, $140-$ $141,2002$.

12) Eguro, T., Ogawa, M., Maeda, T. and Tanaka, H.: The Surface Observation of Er:YAG Laser Irradiated Polished Titanium, Proceeding of $5^{\text {th }}$ WCOI congress, 622-623, 2002.

13) Hibst, R. and Keller, U.: Experimental studies of the application of the Er:YAG laser on dental hard substances I : Measurement of the ablation rate, Lasers Surg Med 9 : 338-344, 1989.

14) Nelson, J.S., Yow, L., Liaw, L. H., Macleay, L., Zavar, R. B., Orestein, A., Wright, W. H., Andrew, J. J and Berns, M. W.: Ablation of bone and methacrylate by a protptype mid-infrared Erbium:YAG laser, Lasers Surg Med $8:$ 494-500, 1988.

15) Keller, U. and Hibst, R.: Experimental studies of the application of the Er:YAG laser on dental hard substances: II. Light microscopic and SEM investigations, Lasers Surg Med $9: 345-351,1989$.

16) Maeda, T., Eguro, T., Ogawa, M., Yonemoto, K., Nogami, I., Tanaka, H. and Katsuumi, I.: Output energy changes of contact probe for Er:YAG laser. Abstruct of $8^{\text {th }}$ international congress on lasers in dentistry, 73, 2002.

17) Eguro, T., Namekawa, H., Nogami, I., Warita, K. and Maeda, T.: Ablation of dental hard tissue by the KaVo KEY Laser, $J$ J Conserv Dent $38: 1339-1346,1995$. (in Japanese) 